\title{
MULTIPLE PSEUDO-CYSTIC TUBERCULOSIS OF BONE IN AN AGED ADULT
}

By R. J. HARrison, M.R.C.P.

Physician, St. James' Hospital, London

There has been confusion in the nomenclature of tuberculosis of bone since Jungling in 1920 described the radiological appearance of sarcoidosis. He believed it to be tuberculous and called it Osteitis Multiplex Tuberculosa Cystica. Subsequently this term was often applied to cases of tuberculosis of bone with cystic appearances. To avoid this confusion Alexander and Mansuy (1940) recommended that cases of widespread involvement of bone with or without cystic appearance should be called Disseminated Bone Tuberculosis. Komins (1952) suggested that when there were multiple pseudo-cysts the condition should be called Multiple PseudoCystic Tuberculosis of Bone. This is rare and most of the cases described have been in young under-nourished coloured children in whom there has always been a primary infection, usually in the lungs, and the spread has been through the blood stream. Murray (1954) describes the characteristics as follows:

' $\mathrm{I}$. The lesions tend to be simultaneous in onset, and to progress and regress in harmony. They have a predilection for the long bones particularly the tibia but concomitant involvement of the short bones and the flat bones is also found.

2. The areas of destruction tend to be oval in the long axes of the bone with regular, clearly defined margins in which no early reaction is observed. The lesions are thus pseudo-cystic in appearance.

3. Fusiform expansion of the bone may come later, and is likely to be associated with an overlying lamellar periostitis.

4. The epiphysis usually, but not invariably, offers a barrier to the spread of infection, unlike the more common solitary metaphyseal focus.

5. Joint involvement is uncommon, but when it does take place mobility is not permanently impaired.

6. Erosion of the cortex is almost invariable. This leads to the formation of abscesses which often break down to form discharging sinuses. Sequestrum formation is extremely rare.'
The following case of an aged adult with Multiple Pseudo-cystic Tuberculosis of Bone has most of these characteristics.

In 1945, a woman who was then aged 79, noticed a discharging swelling in her left groin. It was found to be a chronic abscess suspiciously like a tuberculous one, though no T.B. could be demonstrated. Not long afterwards a similar swelling appeared on the right leg. Previously she had felt well, there was no history of tuberculosis in the family, and she did not know of any contact with tuberculosis. Between $195^{\circ}$ and $195^{2}$ numerous sinuses broke out in other parts of the body, and her general condition deteriorated. She could not remember in which order these sinuses appeared.

On February 12, 1952, she was admitted to St. James' Hospital, Balham, with a fluctuating swelling in the right axilla, discharging sinuses on both sides of the neck (Fig. I). In the right palm, in the left groin, over the left knee and over both tibiae (Fig. 2). There were scars over the left upper chest, in the left axilla (Fig. I), in both groins and on both feet. The abscess over the left tibia was incised; it contained thick pus in a subperiosteal cavity lined with granulation tissue, which was shown to be tuberculous on section. No organisms were seen on a film of the pus; tubercle bacilli only were grown from it. The Mantoux Test was positive I to $I, 000$. No tubercle bacilli were grown from the urine. The E.S.R. Westergren was $55 \mathrm{~mm}$. in one hour. W.R. negative.

Streptomycin 0.5 g. 12 hourly and paraaminosalicylic acid (P.A.S.) $20 \mathrm{~g}$. in five doses daily were commenced on February 22, 1952. P.A.S. was stopped on March 21, 1952, but the streptomycin was continued for 65 days. The patient's general condition steadily improved, and the large fluctuating swelling in the right axilla subsided without breaking down. The sinus on the palm of the right hand (Fig. 4) was closed by March I I, 1952, that on the left groin by March I 8, 1952, and the sinuses on both shins were healed by 


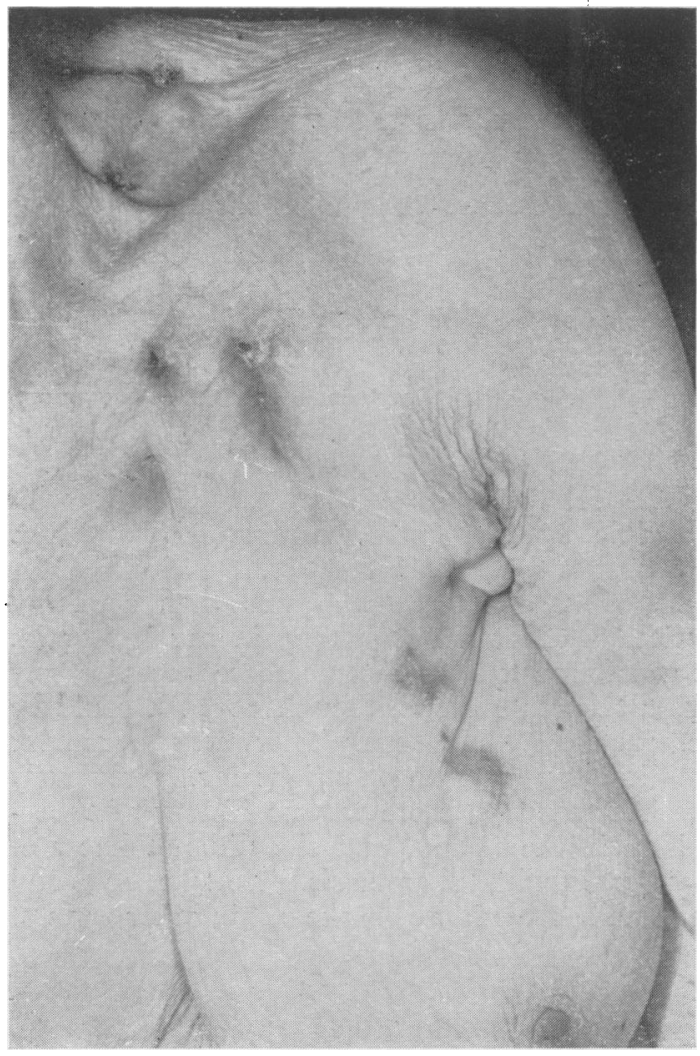

Fig. 1.-Discharging sinuses on both sides of the neck: scars over left upper chest and axilla.

May 6, 1952. The swelling on the left thigh and the discharge from the sinus to the inner side of the left knee lessened. On June 2, I952, Io c.c. of 5 per cent. streptomycin was inserted into the sinus to the inner side of the left patella. This sinus extended upwards for $7 \mathrm{~cm}$. The discharge from it ceased on July 24, 1952. The E.S.R. Westergren was then II $\mathrm{mm}$. in one hour. The patient felt much better and was up for seven hours a day.

The sinus over the right tibia began to discharge slightly on September 12, 1952. On November 17, 1952, the abscess to the inner side of the left patella re-appeared, and large quantities of pus were aspirated from it on three occasions. Tubercle bacilli were grown from this pus which was otherwise sterile. Streptomycin 0.5 g. I2 hourly and P.A.S. 20 g. in 5 doses daily were commenced on November 20, 1952. P.A.S. was stopped on November 24, 1952, because of nausea and vomiting, but streptomycin was continued for 90 days. The abscess subsided and the general condition improved again. On February I4, 1953, a gland in the right submaxillary region

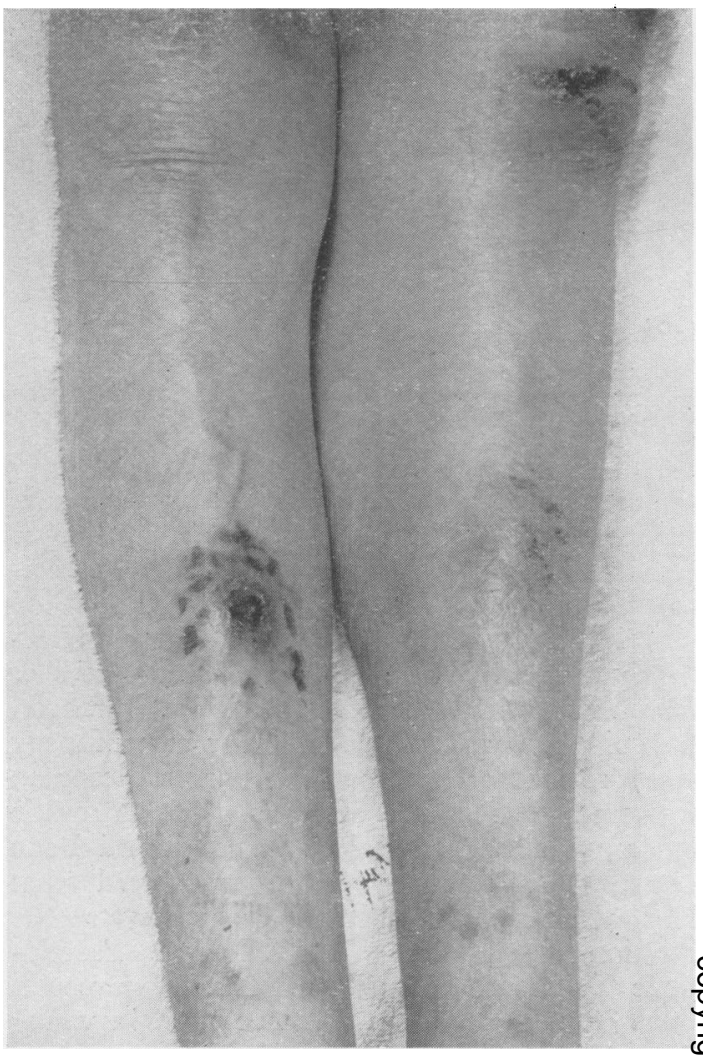

Fig. 2.-Discharging sinuses of left knee and both tibiae.

enlarged, but soon subsided. On March I3, 1953, there was slight tenderness and induration to the inner side of the left knee, which also quickly subsided. No further swelling appeared until January 27, 1954, when a small fluctuating area with surrounding "induration appeared just below the left groin; 3 c.c. of thick pus was aspirated from it, and tubercle bacilli of human type were grown from this pus. Their sensitivity was-Streptomycin-sensitive to $3 \mu \mathrm{g}$. per ml.; P.A.S. to $2 \mu \mathrm{g}$. per $\mathrm{ml}$.; Isoniazid to $0.2 \mu \mathrm{g}$. per $\mathrm{ml}$. Streptomycin 0.5 g. 12 hourly and P.A.S. 10 g. in five doses daily were given from January 26 , to April 26, 1954. By March I I, 1954, the abscess had subsided. The general condition of the patient was then fairly good, and there were no more recurrences. She died on June 2, 1954, at the age of 88 , from bronchopneumonia and congestive heart failure.

\section{Radiological Appearances}

February 5, 1952. Dr. R. L. Quilliam

The right tibia (Fig. 3) shows a cyst-like appearance with some surrounding sclerosis. 


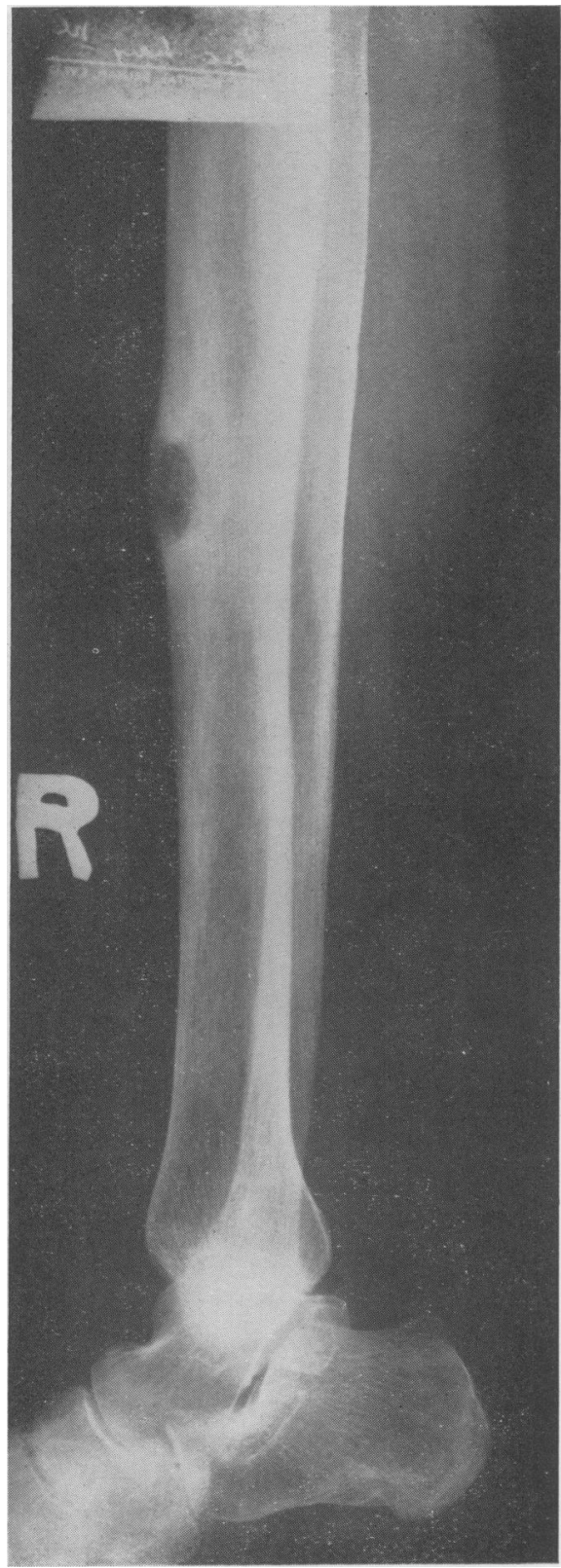

FIG. 3.-Radiograph of right tibia showing a cyst like appearance, with some surrounding sclerosis: there is expansion of the bone at this site, and soft tissue swelling over it.

There is expansion of the bone at this site, and soft tissue swelling over it.

The left tibia shows similar though less marked appearances. There is periostitis over the front of the bone, there is another similar lesion higher on the anterior tibial margin.

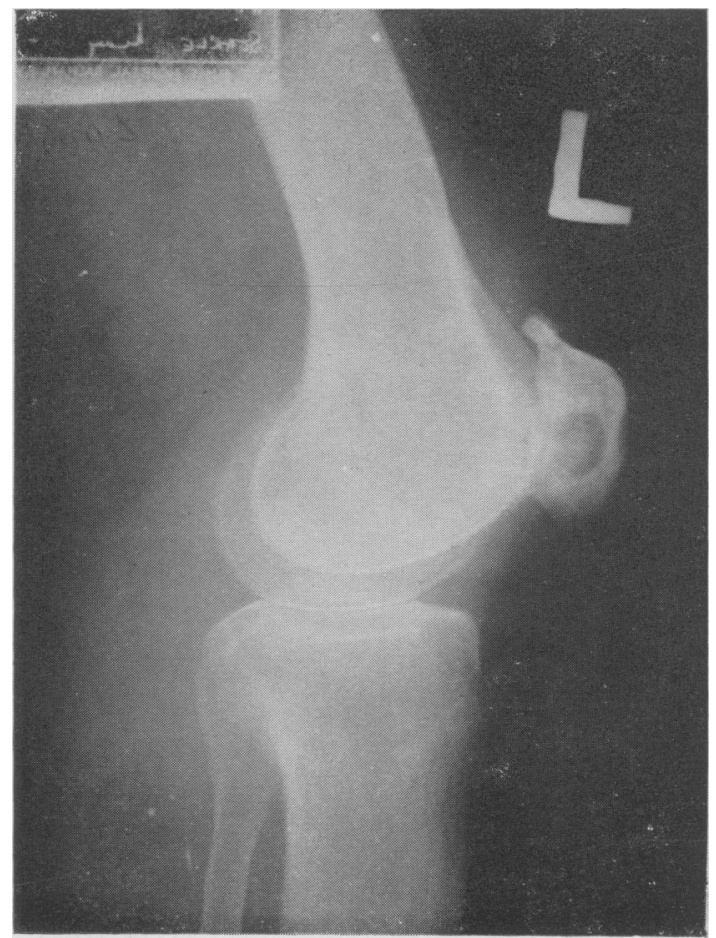

FIG. 4 (February 1952).-A typical tuberculous area of rarefaction in the left patella. A cyst in the shaft of the left femur is obscured by the marker.

There is a typical tuberculous area of rarefaction in the left patella (Fig. 4). The cyst in the shaft of the left femur is obscured by the marker.

Left hip joint normal. No evidence of focus in left femoral head.

May 20, 1952

Right hand (Fig. 6) base of 3 rd metacarpal shows rarefaction and slight expansion, there is a smaller lesion at the base of the and metacarpal. There are small cystic changes in the semi-lunar and os magnum, the joint spaces are narrowed; the carpal appearances are likely to be osteo-arthritic in origin.

No definite lesions are detected in the ribs. The bones generally show some osteoporosis. There is Paget's disease of osteolytic type involving L.4 and 5, and the whole of the sacrum. Skull: no evidence of Paget's disease.

Chest-Dorsal scoliosis to right. Heart slightly enlarged with calcification in the aorta. The lung fields show bronchitic changes only.

\section{November, $195^{2}$}

The focus in the left patella now shows definite improvement: the cyst in the shaft of the left 


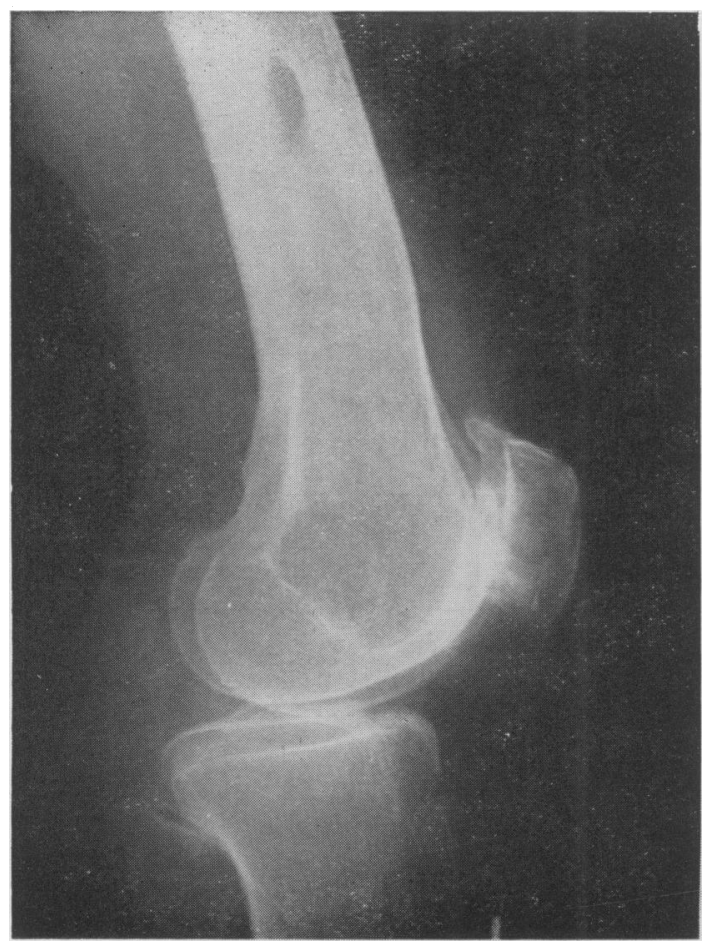

FIG. 5 (November I952).-Focus in left patella shows definite improvement: the cyst in the shaft of the femur has well sclerosed margins.

femur (Fig. 5) (obscured by marker in Fig. 4) has well sclerosed margins, and has probably filled in to its maximum degree.

Feet: grossly decalcified bone. There is erosion of the first right metatarsal head and considerable arthritic changes.

The following are the relevant post-mortem findings (June 3, 1954) (Dr. P. W. Kippax). (Where the organs and systems are omitted, no striking pathological changes were demonstrated.)

Lungs. Confluent bronchopneumonia throughout right lower and middle lobes, and in the lower part of the right upper lobe. Small whitish subpleural deposits in the right interlobar fissure, suggesting tubercles. Histologically, oedema and organising bronchopneumonia. No histological evidence of tuberculosis.

Heart. Pericardium thickened and adherent throughout. Myocardium flabby. Histologically, the pericardium showed fibrous thickening with patchy lymphocyte and plasma cell infiltration. The myocardium showed fibrosis.

Bones and foints. Left patella fixed in fibrous tissue. Left knee osteo-arthritic, with much periarticular thickening.

Left hip and joint: The acetabulum showed a

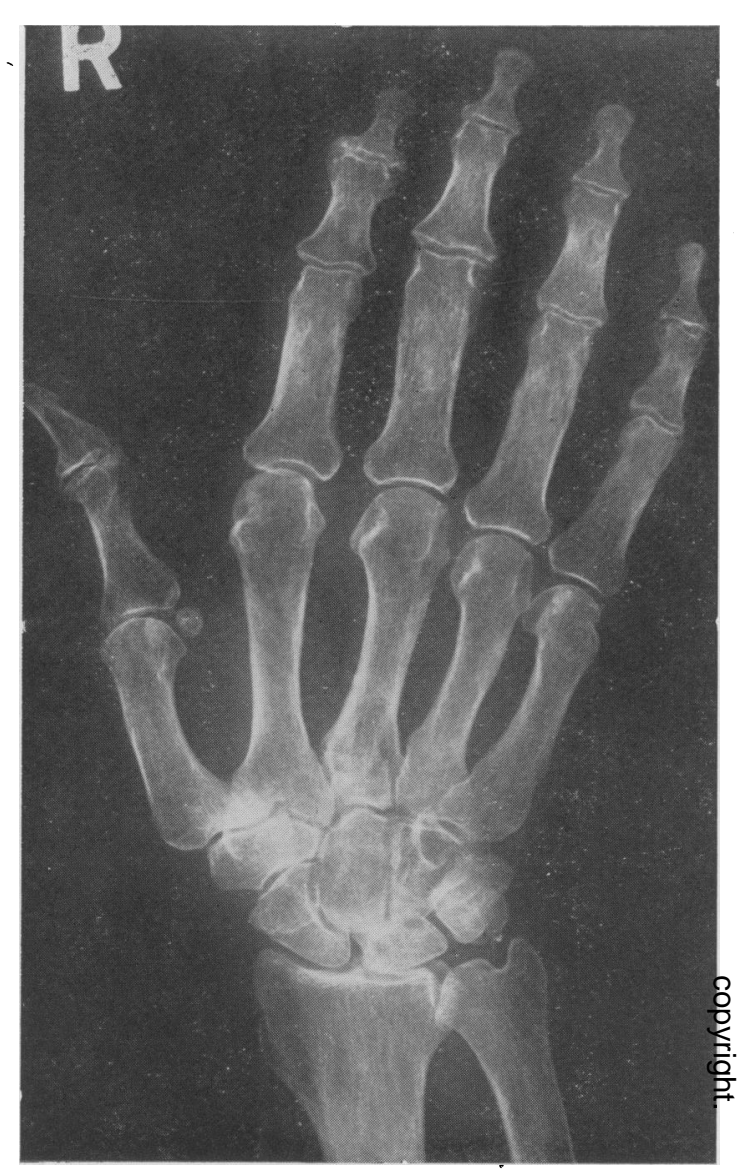

FIG. 6.-There is rarefaction and slight expansion at the base of the 3 rd metacarpal, with a smaller lesion at the base of the 2nd metacarpal; there are small cystic changes in the semilunar and os magnum, the joint spaces are narrowed; the carpal appearances are likely to be osteo-arthritic in origin.

granulomatous process, histologically villous synovitis. On the articular surface of the femoral head there was a peripheral erosion, and there was a central erosion corresponding to the area of synovial granuloma. Histological examination of the femoral head showed areas of decalcification with thinning of the cortical bone, but no specific evidence of tuberculosis.

\section{Comments}

The lesions are similar to those described by Komins. They are pseudocystic in appearance with little sclerosis, the cortex is eroded with abscess formation and discharging sinuses, but no sequestra. They occurred in both long and short bones, including the patella, a rare site for tuberculosis. The involvement of the hip joint was late. Sinuses in this condition are not 
necessarily associated with a bone focus, they may result from a synovial infection or a breaking down gland.

The resistance of normal bones to tuberculosis is high; they are attacked when their resistance is lowered by tuberculous toxaemia, by tubercle bacilli disseminated in the blood stream. In this case there was no evidence of pulmonary tuberculosis, clinically, radiologically or post-mortem. The primary site must have involved the lymph nodes.

Primary infections can occur in old age; Pagel (1953) states that typical primary complexes, recently acquired, are met with in adults of all ages; one of his cases concerned a man aged 64 ; he also cites a patient aged 80 reported by Terplan (I940).

There is some evidence that resistance to tuberculosis is lowered in old age. Arnstein (I94I) states that the process of 'endogenous lymphoglandular recrudescence ' is a typical event in old age tuberculosis.

The pseudo-cystic appearances in the bones in sarcoidosis are almost entirely confined to the phalanges; in this case there were no cystic changes in the phalanges and also tubercle bacilli were demonstrated.

\section{Summary}

Multiple pseudo-cystic tuberculosis of bone occurring in an aged adult is described.

It is emphasised that sinuses in this condition may result from synovial infection or a breaking down gland, and not necessarily from a bone focus.

In sarcoidosis the pseudo cystic appearances are almost entirely confined to the phalanges.

I am grateful to Dr. M. Walker for her help; to Dr. R. O. Murray for his interest and useful criticisms; and Miss E. Mason for the photographs.

\section{BIBLIOGRAPHY}

ALEXANDER and MANSUY, M. N. (1950), Radiology, 4, 839. ARNSTEIN, A. (194I), Tubercle,, 22, 281 .

JUNGLING, O. (1920), Fortschr. Rontgenstr., 27, 375

KOMINS, C. (1952), Brit. Four. Radiology, 25, 1 .

MURRAY, R. O. (1954), Proc. Royal Soc. Med., 47, I 33

PAGEL, W. (1953), 'Pulmonary Tuberculosis,' Oxford Univ. Press,

TERPLAN, K. (1940), Am. Rev. Tuberc., 46, Supplens XLII.

\section{Mlanufacturers " Mote}

Boots Pure Drug Company Limited announce the availability of the following Boots Hydrocortisone Topical Preparations:

\begin{tabular}{|c|c|c|c|}
\hline & & & \\
\hline & & & \\
\hline i & $1 \%$ & $\begin{array}{r}5 \mathrm{~g} . \\
\mathrm{I} 5 \mathrm{~g} .\end{array}$ & $\begin{array}{r}\text { 5s. } 3 \mathrm{~d} \\
\mathrm{I} 3 \mathrm{~s} . \\
3 \mathrm{~d}\end{array}$ \\
\hline Iydrocortistab & & & \\
\hline it . . & $2.5 \%$ & $\begin{array}{r}5 \mathrm{~g} . \\
\mathrm{I} 5 \mathrm{~g} .\end{array}$ & $\begin{array}{l}\text { I2s. od } \\
\text { 29s. } 6 \mathrm{~d}\end{array}$ \\
\hline ydrocr & & & \\
\hline Eye Ointn & $2.5 \%$ & $3 \mathrm{~g}$. & 8s. od. \\
\hline ydroc & & Bot & \\
\hline $\mathrm{F}$ & $1 \%$ & $3 \mathrm{cc}$ & \\
\hline
\end{tabular}

\section{NUTINAL-BOOTS}

Nutinal Tablets each contain I mg. of benactyzine hydrochloride. This drug raises the threshold below which external sources of anxiety produce psychosomatic tension. It is indicated in the treatment of psychoneuroses especially if they are associated with anxiety, depression, obsessivecompulsive traits and psychosomatic symptoms, such as palpitation, sweating and facial flushing. 'The normal dosage range is $\mathrm{I}$ to $3 \mathrm{mg}$. three times daily. Nutinal is supplied in bottles of 100 tablets.

Basic N.H.S. Price-3s. $4 \frac{1}{2}$ d. per bottle of 100 tablets.

\section{NEOMYCIN-BOOTS}

This antibiotic is particularly valuable for the local treatment of pyogenic skin diseases and for the control of eye infections. Conditions which have responded to Neomycin include impetigo, folliculitis barbae, sycosis barbae, ecthyma, eczematoid dermatitis, furunculosis, hordeolum, blepharitis, otitis externa, and secondarily-infected dermatoses, wounds and burns. NeomycinBoots is available in two forms, each of which contains $5 \mathrm{mg}$. neomycin sulphate per gramme.

(b) Neomycin eye ointment .. .. 4 g. Is. 8 d.

Literature on these Boots Products may be obtained on request from the makers. 